\title{
PERAN PERIKANAN TANGKAP SKALA KECIL DALAM PEMBANGUNAN KAWASAN DI WERU KOMPLEK, KABUPATEN LAMONGAN
}

\author{
Role of Small-scale Fishery in the Regional Development \\ of 'Weru Complex', Lamongan Regency
}

\author{
*Budi Wardono' dan Toha Muslih ${ }^{2}$ \\ ${ }^{1}$ Balai Besar Riset Sosial Ekonomi Kelautan dan Perikanan \\ Gedung BRSDM KP I Lt. 4, Jalan Pasir Putih Nomor 1 Ancol Timur, Jakarta Utara, Indonesia \\ Telp: (021) 64711583 Fax: 64700924 \\ ${ }^{2}$ Penyluluh Perikanan Kabupaten Lamongan \\ Jl. Sumargo No.2, Kaloharjo, Sidoharjo, Kabupaten Lamongan, Jawa Timur 62217, Indonesia \\ Diterima tanggal: 7 November 2018 Diterima setelah perbaikan: 25 Mei 2020 \\ Disetujui terbit: 25 Juni 2020
}

\begin{abstract}
ABSTRAK
Pengembangan perikanan skala kecil diarahkan untuk menciptakan keterkaitan yang kuat dengan sektor lain. Keterkaitan untuk peningkatan nilai tambah, penyerapan tenaga kerja dan peningkatan pendapatan yang akhirnya mampu menumbuhkan perekonomian lokal. Selama ini peranan tengkulak masih sangat dominan, di sisi lain peranan istri/wanita nelayan semakin penting. Istri nelayan nelayan memainkan peranan dalam pengelolaan hasil usaha penangkapan. Semakin pentingnya peranan istri nelayan dalam pengelolaan usaha penangkapan dapat mengurangi dominasi tengkulak/'langgan' dalam sistem bisnis perikanan. Penelitian ini bertujuan untuk menganalisis peranan perikanan kecil dan peran "mapak" oleh istri nelayan. Penelitian dilakukan di Kawasan Weru Komplek, Kecamatan Paciran, Kabupaten Lamongan, pada bulan Januari-April tahun 2015 dan November 2019. Data yang digunakan adalah data primer pelaku usaha yang meliputi usaha penangkapan, pemasaran, pengolahan produk dan peranan "mapak" istri nelayan dalam manajemen usaha. Analisis yang digunakan adalah analisis deskriptif, hasilnya dalam bentuk tabel dan gambar. Hasil penelitian menunjukkan bahwa karakteristik nelayan dan kondisi sumberdaya menentukan perilaku terhadap pemanfaatan sumberdaya. Interaksi tersebut sebagai sumber kegiatan ekonomi yang mampu mendorong pertumbuhan ekonomi lokal. Perikanan skala kecil mampu menjadi penggerak perekonomian wilayah di Weru komplek melalui kemampuannya menggerakkan keterkaitan ke belakang dan kedepan (upstream dan downstream). "Mapak" merupakan peran yang dilakukan Isteri nelayan dalam manajemen usaha hasil penangkapan yaitu melakukan grading, pemasaran, pengolahan produk dan yang paling utama adalah pengelolaan keuangan hasil usaha. Istri nelayan/wanita nelayan juga memainkan peranan dalam pembentukan modal melalui arisan, tabungan dan permodalan KUR. Keberhasilan istri nelayan/wanita nelayan menjalankan fungsi "mapak" mampu mengurangi dominasi peran tengkulak/langgan dalam usaha perikanan.
\end{abstract}

Kata Kunci: perikanan skala kecil; ekonomi lokal; “mapak”; tengkulak; KUR

\begin{abstract}
Small-scale fisheries development is directed to create strong linkages with other sectors. Linkages to increase added value, employment and incomes are ultimately expected to grow local economy. By far, middlemen have been playing dominant role, but on the other hand, the role of both fishers' wives and women fishers have been increasingly significant. These women contributed to the management of fishing results. The more significant of their role the more reducing the dominance of middlemen in the fisheries business system. The research objective was to analyze the role of small-scale fisheries and the role of "mapak" by fishers' wives. The study was conducted in Weru Complex, Paciran Subdistrict, Lamongan District, in January to April 2015 and November 2019. The study used primary data that were collected from business actors from fishing, marketing, product processing sector and the role of "mapak" in business management. Data were analyzed with descriptive method, and the results were described in tables and figures. The results suggested that fishers' characteristics and resources condition determine the behaviour towards resources. This interaction is a source of economic activity which is able to encourage local economic growth. Small-scale fisheries is able to drive regional economic in Weru complex through its ability to move backward and
\end{abstract}


forward linkages (upstream and downstream). "Mapak" is the role of fishers' wives in the management of fish caught including grading, marketing, product processing and especially in the financial management of the activities. Furthermore, they also contribute to capital arrangement through social gathering, savings, and bank capital. Their succeed role eventually reduce the dominance of the role of middlemen / customers in fishery business.

Keywords: small-scale fisheries; local economy; “mapak”; middlemen; KUR

\section{PENDAHULUAN}

Perikanan tangkap skala kecil masih mendominasi armada penangkapan di Indonesia (KKP, 2019). Oleh karena itu perikanan skala kecil memainkan peranan penting dalam kehidupan masyarakat di pantai utara Jawa (Fauzi \& Anna, 2010; Sudarmo, Baskoro, Wiryawan, Wiyono \& Monintj, 2015; Anna. 2014). Peningkatan kontribusi secara langsung menunjukkan terjadi peningkatan produksi, pendapatan, perluasan lapangan kerja dan nilai tambah. Meskipun mempunyai peranan yang besar, perikanan skala kecil masih mempunyai permasalahan yang kompleks yang menyebabkan tekanan untuk mempertahankan sumber mata pencaharian (Sudarmo et al., 2015; Fauzi \& Anna, 2010; Kramer, Simanjuntak \& Liese, 2002; Sievanen, 2014). Permasalahan yang dihadapi antara lain persaingan dengan wisata pantai dan sektor perikanan lainnya, penurunan stok ikan, variabilitas iklim, dan fluktuasi pasar (Sievanen, 2014).

Permasalahan utama dalam perikanan tangkap adalah besarnya tekanan terhadap sumber daya perikanan yang mengakibatkan terjadinya penurunan kualitas dan kuantitasnya. (Fauzi, 2010). Menurut data FOA tahun 2007 dalam Fauzi (2010) sekitar $28 \%$ dari stok ikan dunia sudah berada dalam kondisi over exploited maupun depleted (terkuras) dan $52 \%$ dalam kondisi fully exploited. Data Komisi Nasional Pengkajian Stok Ikan Nasional (Komnaskajiskan) menyajikan kondisi serupa juga terjadi pada perikanan Indonesia. Hal tersebut disebabkan karena dua hal utama yaitu overfishing dan ekses kapasitas (over capacity) (Fauzi, 2010). Menurut Sangun, Gumey \& Berk (2018) telah terjadi inefisiensi sumberdaya pada perikanan di Turki, dimana untuk menghasilkan output yang sama, penggunaan input dapat dikurangi sebesar $36,1 \%$. Input utama yang mengarah ke inefisiensi dalam kinerja output nelayan skala kecil adalah pengeluaran pemeliharaan kapal, perbaikan alat penangkapan ikan atau pengeluaran pembelian dan biaya tenaga kerja (12\%) (Sangun, Güney, \& Berk, 2018).
Permasalahan statistik perikanan skala kecil terkait pencatatan hasil penangkapan. Perikanan tangkap skala kecil dan perikanan non-komersial, terutama di dekat pantai, telah diakui sebagai dasar untuk alasan sosial, budaya, dan keamanan pangan, namun hasil tangkapannya jarang diperhitungkan dalam statistik resmi (Zeller, Booth, Davis \& Pauly, 2006), dengan demikian kontribusinya sering tidak dipertimbangkan.

Pengembangan sektor perikanan diarahkan untuk meningkatkan peran dalam menciptakan keterkaitan yang kuat dengan sektor lain baik keterkaitan ke depan maupun keterkaitan kebelakang melalui peningkatan nilai tambah, penyerapan tenaga kerja dan peningkatan pendapatan yang pada akhirnya mampu menumbuhkan perekonomian melalui efek pengganda (multiplier effect) baik dampak langsung, dampak tak langsung maupun dampak ikutan. Pentingnya perikanan tangkap skala kecil bagi perekonomian lokal atau nasional, tidak hanya mencakup tenaga kerja yang diciptakan dalam sektor itu sendiri (Bene, 2006), tetapi juga terhadap yang diciptakan di sektor-sektor terkait lainnya. Hal ini berkaitan dengan konsep keterkaitan hulu dan hilir.

Kegiatan hulu adalah kegiatan-kegiatan memasok masukan atau input kepada sektor penangkapan. Banyak input yang biasanya disediakan oleh individu skala kecil atau usaha mikro terletak di dekatnya dalam wilayah pedesaan setempat, meskipun beberapa hal misalnya alat penangkapan ikan dan bahan bakar (diproduksi pihak lain yang lebih jauh baik nasional maupun internasional) namun disediakan secara lokal melalui bisnis lokal/pedagang. Hubungan keterkaitan ke depan juga terjadi pada perikanan skala kecil tersebut. Pelaku usaha skala kecil atau perusahaan biasanya memberikan banyak input ke sektor hilir dalam kegiatan wilayah pedesaan setempat. Keterkaitan ke hilir ini akan mampu menggerakkan perekonomian lokal, bahan baku ikan hasil penangkapan akan menghasilkan penjualan, pendapatan dan pekerjaan di tingkat lokal, dan hal 
ini akan berputar terus dan akan menghasilkan multiplier effect selama perputaran uang masih berlangsung dilokasi tersebut. Menurut Bene (2006), studi empiris penghitungan keterkaitan hulu hilir perikanan skala kecil di negara berkembang masih sedikit, namun tambahan tenaga kerja yang diciptakan melalui keterkaitan hulu dan hilir cukup signifikan.

Tujuan penelitian untuk menganalisis peranan perikanan kecil dan peran "mapak" oleh istri nelayan. Analisis keterkaitan perikanan skala kecil dalam perekonomian tersebut diharapkan mampu menjadi prime mover dalam pembangunan wilayah di Kabupaten Lamongan. Penelitian ini menghasilkan strategi kebijakan yang bisa menjadi salah satu instrumen dalam pengembangan perikanan tangkap skala kecil sehingga mampu memberikan peran sebagai pendorong utama (prime mover) pembangunan perekonomian wilayah.

Penelitian dilakukan di Desa Weru Komplek, Kecamatan Paciran Kabupaten Lamongan. Kawasan Weru Komplek adalah suatu kawasan yang terdiri dari 4 desa yang mempunyai tempat pendataran ikan (TPI), pasar tempat transaksi hasil tangkapan yang sama, dimana nelayan skala kecil melakukan aktifitas penangkapan selanjutnya aktifitas pemasaran dan pengolahan hasil perikanan berada pada lokasi yang sama.

Pemilihan lokasi tersebut didasarkan pada beberapa pertimbangan sosial ekonomi dan karakteristik sumber daya dan pelaku usaha.
Kabupaten Lamongan mempunyai potensi perikanan yang tinggi, usaha penangkapan terpusat di perairan Laut Jawa (WPP 712) pada wilayah Kecamatan Brondong dan Kecamatan Paciran, yang memiliki 1 (satu) Pelabuhan Perikanan Nasional (PPN) Brondong dan 4 (empat) Tempat Pendaratan Ikan (TPI), yaitu mulai dari arah timur ke barat TPI Weru Komplek, Kranji, Labuhan dan Lohgung. Potensi dan kinerja perikanan tangkap kabupaten Lamongan tahun 2014 sebagai berikut: Potensi Produksi 100.000 ton; Produksi sebanyak 70.150 ton (2014) dan 76.836 ton (2018); Nilai 806,382 milyar dan jumlah Nelayan 28.154 orang, dan jumlah armada 7.527 unit (besar dan kecil, sebagian besar nelayan skala kecil), (DKP. Kab. Lamongan, 2014). Pada tahun 2018 jumlah usaha pengolahan sebanyak 1211 unit (yang didominasi oleh usaha mikro, kecil dan menengan (UMKM).

Penelitian dilakukan pada bulan JanuariApril 2015 dan diupdate dengan data bulan November 2019. Responden adalah nelayan skala kecil, pelaku usaha penangkapan, pedagang/ tengkulak, Istri nelayan/wanita nelayan yang berperan sebagai manajer usaha di lokasi penelitian.

Data yang diperlukan dalam penelitian ini adalah data primer dan data sekunder. Data primer yang dikumpulkan antara lain tentang usaha penangkapan dari penggunaan input: $\mathrm{BBM}$, perbekalan, $\mathrm{ABK}$, alat penangkapan ikan, daerah penangkapan, jenis kapal yang digunakan, sumber permodalan, pemasasaran dan lain-lain.

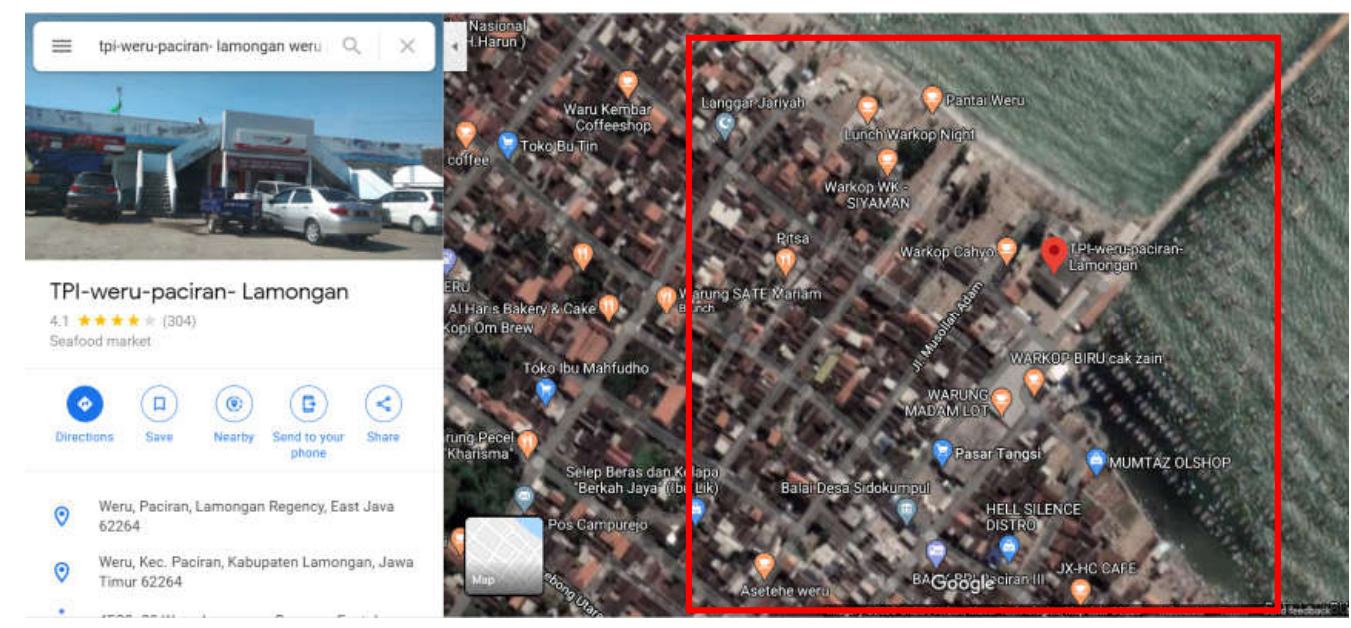

Gambar 1. Lokasi penelitian Weru Komplek (Desa Waru, Weru Lor, dan Sidokumpul), Kecamatan Paciran, Kabupaten Lamongan.

Figure 1. Weru Komplek Research Location, (Waru Vilage, Weru Lor, dan Sidokumpul), Paciran District, Lamongan Regency.

Sumber: Google Maps/Source: Google Maps 
Data sekunder yang kumpulkan adalah statistik produksi berdasarkan jenis alat penangkapan ikan dan ukuran kapal. Data primer dikumpulkan dengan menggunakan kuesioner yang telah disiapkan, sedangkan data skunder dikumpulkan dari Dinas/Instansi terkait.

Analisis data dilakukan dengan pendekatan analisis diskriptif dari hasil wawancara dengan narasumber dan responden. Hasilnya dituangkan dalam bentuk tabel, gambar dan grafik. Hasilnya berupa sintesa hasil analisis berdasarkan hasil temuan lapangan dikombinasikan dengan hasil telusur pustaka yang relefan. Hasil akhir berupa usulan rekomendasi untuk memperkuat peranan perikanan skala kecil dan peran pelaku usaha (nelayan, istri nelayan, pengolah, pemasar, pedagang) sehingga mampu memberikan kontribusi dalam pembangunan wilayah.

\section{SUMBER DAYA DAN KARAKTERISTIK PERIKANAN TANGKAP SKALA KECIL DI KABUPATEN LAMONGAN}

Pelaku usaha perikanan tangkap skala kecil yang berbasis di sepanjang pantai utara Jawa di Kabupaten Lamongan (Kecamatan Paciran dan Kecamatan Brondong). Karakteristik spesifik pelaku usaha di Lamongan tertera pada Tabel 1. Karakteristik perikanan skala kecil di
Lokasi penelitian terdapat 13 indikator. Indikator tersebut dapat dikelompokkan menjadi: Indikator kepemilikan kapal dan alat penangkapan ikan (kepemilikan dan ukuran kapal; jenis alat penangkapan ikan dan klasifikasi alat penangkapan ikan); Hasil tangkapan, pengolahan dan pemasaran; Inevstasi, pendapatan.

Struktur armada penangkapan ikan di Indonesia sebagian besar menggunakan kapal berukuran kecil (kurang dari 10 GT) (KKP, 2019). Armada penangkapan di kedua lokasi penelitian mempunyai karakteristik yang berbeda. Armada di Lamongan sebagian besar terdiri dari kapal tradisonal yang sudah sejak lama beroperasi di wilayah Lamongan. Kondisi armada perikanan tangkap di lokasi penelitian sebagian besar didominasi oleh armada berukuran kecil (kurang dari 5 GT) sebesar $64,17 \%$.

Aktifitas perekonomian yang bersumber dari perikanan tangkap laut di Kabupaten Lamongan terutama berpusat di Pelabuhan Perikanan Nasional (PPN) Brondong, Tempat Pelelangan Ikan (TPI) Labuhan, TPI Loh Gung, TPI Kranji, dan TPI Weru Komplek. Produksi perikanan di Lamongan tahun 2018 sebesar lebih kurang 76.863 ton memberikan share $17 \%$ dari total produksi ikan di Jawa Timur. Jumlah Produksi Perikanan di Kabupaten Lamongan tahun 2014-2108 seperti Tabel 2.

Tabel 1. Karakteristik Perikanan Tangkap Skala Skala Kecil di lokasi Penelitian (Weru Komplek). Table 1. Characteristics of Small-Scale Capture Fisheries in Reseach Location (Weru Complex).

\begin{tabular}{|c|c|c|c|}
\hline No & $\begin{array}{l}\text { Karakteristik Perikanan/ } \\
\text { Fisheries Characterictics }\end{array}$ & $\begin{array}{l}\text { Katagori/ } \\
\text { Catagory }\end{array}$ & $\begin{array}{l}\text { Keterangan/ } \\
\text { Description }\end{array}$ \\
\hline 1. & $\begin{array}{l}\text { Kepemilikan kapal dan } \\
\text { alat penangkapan ikan/ } \\
\text { Ownership of vessels and } \\
\text { fishing gear }\end{array}$ & $\begin{array}{l}\text { Biasanya dimiliki oleh perorangan } \\
\text { Kerjasama operasional /individual } \\
\text { or joint operational }\end{array}$ & Perorangan/Individual \\
\hline 2. & $\begin{array}{l}\text { Ukuran Kapal/Perahu (Gross } \\
\text { ton)/Boat size/GT }\end{array}$ & $\begin{array}{l}\text { Kecil, mesin di dalam (atau motor } \\
\text { tempel)/Small, outboard motor }\end{array}$ & $\begin{array}{l}\text { Perahu motor tempel (PMT) dan } \\
\text { kapal motor (KM) kurang dari } 10 \mathrm{GT} / \\
\text { Outboard motor and motorboats less } \\
\text { than } 10 \mathrm{GT}\end{array}$ \\
\hline 3. & $\begin{array}{l}\text { Jenis-jenis penangkapan } \\
\text { ikan/ Types of fishing gear }\end{array}$ & $\begin{array}{l}\text { Jaring ikan/fishing net: Minitrawl } \\
\text { (payang), Gillnet, purseseine }\end{array}$ & $\begin{array}{l}\text { Jaring ikan/fishing net: Minitrawl } \\
\text { (paying), Gillnet, purseseine }\end{array}$ \\
\hline 4. & $\begin{array}{l}\text { Klasifikasi penangkapan } \\
\text { ikan/ Classification of fishing } \\
\text { gear }\end{array}$ & $\begin{array}{l}\text { Mekanik dan manual/ Mechanical } \\
\text { and manual }\end{array}$ & $\begin{array}{l}\text { Mekanik dan manual/ Mechanical and } \\
\text { manual }\end{array}$ \\
\hline 5. & $\begin{array}{l}\text { Komitmen waktu / Time } \\
\text { commitment }\end{array}$ & $\begin{array}{l}\text { Biasanya waktu penuh atau paruh } \\
\text { waktu/ Usually full time or part time }\end{array}$ & $\begin{array}{l}\text { Sebagian besar nelayan penuh/ Mostly } \\
\text { fishermen are fulltime }\end{array}$ \\
\hline 6. & $\begin{array}{l}\text { Nilai Investasi/ The amount } \\
\text { of investment }\end{array}$ & $\begin{array}{l}\text { Rendah sampai sedang, semuanya } \\
\text { oleh operator/ Low to moderate, all } \\
\text { by the operator }\end{array}$ & $\begin{array}{l}\text { Rendah sampai sedang/Low to } \\
\text { moderate }\end{array}$ \\
\hline 7. & $\begin{array}{l}\text { Hasil Tangkapan (per unit } \\
\text { perikanan)/Cath }\end{array}$ & Rendah - sedang/Low to moderat & Rendah - sedang/Low to moderate \\
\hline 8. & $\begin{array}{l}\text { Cara Penjualan hasil } \\
\text { tangkapan/Sales method }\end{array}$ & $\begin{array}{l}\text { Diorganisisr penjual lokal/ } \\
\text { Organized by local traders }\end{array}$ & $\begin{array}{l}\text { Dijual ke tengkulak dan ke pasar lokal } \\
\text { oleh Istri nelayan/Sold to middlemen } \\
\text { and local markets by fisher's wives }\end{array}$ \\
\hline
\end{tabular}


Lanjutan Tabel 1/Continue Table 1

\begin{tabular}{|c|c|c|c|}
\hline No & $\begin{array}{l}\text { Karakteristik Perikanan/ } \\
\text { Fisheries Characterictics }\end{array}$ & $\begin{array}{l}\text { Katagori/ } \\
\text { Catagory }\end{array}$ & $\begin{array}{l}\text { Keterangan/ } \\
\text { Description }\end{array}$ \\
\hline 9. & $\begin{array}{l}\text { Pengolahan hasil tangkapan/ } \\
\text { Processing }\end{array}$ & $\begin{array}{l}\text { Pengeringan, pengasapan, } \\
\text { penggaraman, kebanyakan untuk } \\
\text { dikonsumsi /Drying, smoking, } \\
\text { salting, mostly for consumption }\end{array}$ & $\begin{array}{l}\text { Pengeringan, pengasapan, } \\
\text { penggaraman, pengolahan menjadi } \\
\text { produk jadi (krupuk, abon, terasi, } \\
\text { pindang)/ Drying, smoking, salting, } \\
\text { processing into finished products } \\
\text { (crackers, shredded, shrimp paste, } \\
\text { boiled) }\end{array}$ \\
\hline 10. & Tingkat pendapatan/ Income & Sedang ke rendah/Medium-low & $\begin{array}{l}\text { Sedang dan rendah sesuai musim/ } \\
\text { Medium and low, depending on the } \\
\text { season }\end{array}$ \\
\hline 11. & $\begin{array}{l}\text { Integrasi ekonomi/ } \\
\text { Integration economy }\end{array}$ & $\begin{array}{l}\text { Sebagian terintegrasi/ } \\
\text { Most inetgrated }\end{array}$ & $\begin{array}{l}\text { Sebagian terintegrasi dengan pasar } \\
\text { regional, sebagian untuk pasar lokal/ } \\
\text { Some are integrated with regional } \\
\text { markets, some for local markets }\end{array}$ \\
\hline 12. & Pekerjaan/Job & Seringkali multi pekerjaan & Nelayan penuh/Fully Fisher's \\
\hline 13. & $\begin{array}{l}\text { Tingkat pemasaran/ } \\
\text { Marketing }\end{array}$ & $\begin{array}{l}\text { Seringkali nasional atau lokal/ } \\
\text { National and local }\end{array}$ & $\begin{array}{l}\text { Pasar lokal dan pasar regional/ } \\
\text { nasional/Local market and regional/ } \\
\text { national market }\end{array}$ \\
\hline
\end{tabular}

Sumber: Hasil pengamatan lapangan dan diskusi dengan nara sumber dan responden/

Source: Field observations and discussions with key persons and respondents

Tabel 2. Produksi Perikanan Tangkap di Kabupaten Lamongan Tahun 2018.

Table 2. Capture Fisheries Production in Lamongan Regency, 2018.

\begin{tabular}{llrrrrr}
\hline \multirow{2}{*}{ No } & Pelabuhan Perikaman/ & \multicolumn{5}{c}{ Produksi/Production (ton) } \\
\cline { 3 - 7 } & \multicolumn{1}{c}{ Fishing Port } & $\mathbf{2 0 1 4}$ & $\mathbf{2 0 1 5}$ & $\mathbf{2 0 1 6}$ & \multicolumn{1}{c}{$\mathbf{2 0 1 7}$} & $\mathbf{2 0 1 8}$ \\
\hline 1. & Lohgung & 326.00 & 93.30 & 582.10 & 636.90 & 713.60 \\
2. & Labuhan & $1,328.00$ & 773.90 & $1,059.20$ & $1,775.40$ & $1,964.80$ \\
3. & Brongdong & $60,379.00$ & $64,326.00$ & $63,873.90$ & $67,889.60$ & $67,615.40$ \\
4. & Kranji & $3,795.00$ & $2,609.80$ & $3,079.90$ & $2,833.90$ & $4,295.80$ \\
5. & Weru komplek & $5,725.00$ & $4,224.00$ & $4,546.90$ & 220.30 & 228.40 \\
& Jumlah/Total & $\mathbf{7 3 , 5 6 7 . 0 0}$ & $\mathbf{7 4 , 2 4 2 . 0 0}$ & $\mathbf{7 5 , 1 5 8 . 0 0}$ & $\mathbf{7 5 , 3 7 3 . 1 0}$ & $\mathbf{7 6 . 8 3 6 , 0 0}$ \\
\hline
\end{tabular}

Sumber: Lamongan dalam Angka, 2019/Source: Lomongan Regency in Figure, 2019

Jumlah produksi perikanan Lamongan meningkat pada periode tahun 2014-2018. Gambaran ini memberikan indikasi bahwa perikanan skala kecil di Lamongan tetap memberikan kondtribusi terhadap perekonomian wilayah.

PPN Brondong merupakan perlabuhan perikanan terbesar di mana kapal-kapal yang beroperasional didominasi kapal berukuran sedang dan besar. Sedangkan produksi di TPI Weru Komplek didominasi oleh perahu/kapal motor berukuran kecil dengan jumlah kapal/perahu sebanyak 788 kapal. Sebaran kapal/perahu untuk aktifitas nelayan seperti tertera pada Tabel 3 .

Kondisi armada perikanan tangkap sebagian didominasi oleh armada berukuran kecil (kurang dari 5 GT) di Lamongan sebesar 64,17\%. Kondisi ini menandakan bahwa peranan perikanan skala kecil masih dominan, oleh karena itu diperlukan perhatian kebijakan yang berpihak kepada perikanan skala kecil.

Penggunaan alat penangkapan ikan nelayan Lamongan menurut Wardono, Fauzi, Fahrudin \& Purnomo (2015) menunjukkan bahwa beberapa alat penangkapan ikan sudah tidak efisien, sehingga penambahan input, menyebabkan produksi tidak akan bertambah sebesar penambahan input. $\mathrm{Di}$ samping sudah tidak efisien, perikanan tangkap skala kecil menghadapi ketidakpastian yang tinggi (Wardono, Fauzi, Fahrudin \& Purnomo, 2015). Namun demikian untuk mengurangi input terutama aset akan mengalami kesulitan. Aset nelayan berupa kapal merupakan aset yang nilainya cukup besar namun tidak mudah untuk menjual kapal ke pihak lain (sulit mengalihfungsikan aset yang sudah dibeli). 
Tabel 3. Jenis Perahu/Kapal Penangkapan Ikan Menurut PPI di Kabupaten Lamongan,Tahun 2018. Table 3. Type of Fishing Boat Based on Fish Auction Port in Lamongan Regency, 2018.

\begin{tabular}{|c|c|c|c|c|c|c|}
\hline \multirow[b]{2}{*}{ No } & \multirow{2}{*}{$\begin{array}{c}\text { Nama Pelabuhan/ } \\
\text { Port Name }\end{array}$} & \multirow{2}{*}{$\begin{array}{c}\text { Perahu Tempel } \\
\text { motor/Outboard } \\
\text { Motor }\end{array}$} & \multicolumn{3}{|c|}{ Perahu Bermotor/Motor Boat } & \multirow[b]{2}{*}{ Total/Total } \\
\hline & & & Besar/Big & $\begin{array}{l}\text { Sedang/ } \\
\text { Medium }\end{array}$ & Kecil/Small & \\
\hline 1 & Lohgung & - & 20.00 & - & 224.00 & 244.00 \\
\hline 2 & Labuhan & - & 26.00 & - & 354.00 & 380.00 \\
\hline 3 & Brongdong & - & 372.00 & 394.00 & 143.00 & 909.00 \\
\hline 4 & Kranji & 519.00 & 54.00 & 22.00 & 406.00 & $1,001.00$ \\
\hline 5 & Weru Komplek & - & 22.00 & - & 788.00 & 810.00 \\
\hline & Jumlah/Total & 519.00 & 494.00 & 416.00 & $1,915.00$ & $3,344.00$ \\
\hline
\end{tabular}

Sumber: Lamongan dalam Angka, 2019/Source: Lomongan Regency in Figure, 2019

Perkembangan ekonomi di Kabupaten Lamongan ditopang oleh jumlah nelayan 28.154 orang; terdapat 10 unit industri pengolahan ikan (UPI), 2011 unit pengolah skala rumah tangga/ UMKM. Berdasarkan pelaku usaha sebagian besar adalah usaha kecil dan menengah (UMKP) dengan jumlah tenaga kerja kurang dari 20 orang per usaha, data pelaku usaha perikanan di Lamongan seperti pada Tabel 4.

Usaha UMKM di Kabupaten Lamongan didominasi jenis usaha tradisional yang memang sudah lama menjadi mata pencaharian masyarakat. Jumlah unit usaha perikanan berjumlah 1211 unit usaha dimana 1201 unit usaha adalah UMKM. Hal ini menunjukkan bahwa usaha perikanan menjadi salah satu sumber usaha dan pendapatan bagi masyarakat.

Peran penting perikanan dalam perekonomian wilayah ditunjukan pada Tabel 5, dimana peran perikanan terhadap PDRB kabupaten Lamongan sharenya sebesar $13,84 \%$ pada tahun 2014 dan meningkat menjadi $16,98 \%$ tahun 2018. Semakin meningkatnya peran perikanan dalam perekonomian kabupaten Lamongan mendorong pemerintah bersama pelaku usaha terus berupaya meningkatkan produksi dan hasil olahan produk perikanan melalui UMKM.

Tabel 4. Jumlah Industri Perikanan Menurut Jenis dan Tenaga Kerja di Kabupaten Lamongan Tahun 2018.

Table 4. Number of Fishing Industry According to Type and Amount of Worker in Lamongan Regency, 2018.

\begin{tabular}{llccr}
\hline \multirow{2}{*}{ No. } & \multicolumn{1}{c}{$\begin{array}{c}\text { Jenis Industri/ } \\
\text { Type of Industry }\end{array}$} & $\begin{array}{c}\text { Jumlah Industri/Ammount of Industry } \\
\text { Kurang } \mathbf{2 0} \text { orang/Less } \\
\text { than } \mathbf{2 0} \text { People }\end{array}$ & $\begin{array}{c}\text { Lebih } \mathbf{2 0} \text { orang/More } \\
\text { than } \mathbf{2 0} \text { People }\end{array}$ & $\begin{array}{c}\text { Jumlah/ } \\
\text { Total }\end{array}$ \\
\hline 1 & Pengeringan/Driying & 185 & 0 & 185 \\
2 & Pemindangan/Boiled fish & 126 & 0 & 126 \\
3 & Pendinginan/Ice & 261 & 0 & 261 \\
4 & Terasi/Shrimp paste & 90 & 0 & 90 \\
5 & Petis/Fishpaste & 45 & 0 & 45 \\
6 & Pengasapan/Smoked & 278 & 0 & 278 \\
7 & Tepung ikan/Fish flour & 22 & 0 & 22 \\
8 & Kerupuk/Fish crakers & 133 & 0 & 133 \\
9 & Cold Storag/Surimi & 19 & 10 & 10 \\
10 & Bakso ikan/ Nyget/Abon/ & & 0 & 19 \\
& Meatball & 19 & 0 & 19 \\
11 & Otak-otak/Grilled fish cake & 7 & 0 & 7 \\
12 & Presto/Fresto & 16 & 0 & 16 \\
13 & Lain-lain/Other & $\mathbf{1 , 2 0 1}$ & $\mathbf{1 0}$ & $\mathbf{1 , 2 1 1}$ \\
\hline
\end{tabular}

Sumber: Lamongan dalam Angka, 2019/Source: Lomongan Regency in Figure, 2019 
Tabel 5. Share PDRB Berdasarkan Lapangan Usaha di Lamongan Tahun 2007 dan 2014 dan Tahun 2018 (dalam \%).

Table 5. Share of GDP by Industry, 2007, 2014 and 2018 in Lamongan (in \%).

\begin{tabular}{clccc}
\hline \multirow{2}{*}{$\begin{array}{c}\text { Lokasi/ } \\
\text { Districts }\end{array}$} & $\begin{array}{c}\text { Lapangan Usaha/ } \\
\text { By Industry }\end{array}$ & $\begin{array}{c}\text { Share Pertanian dan Perikanan Terhadap PDRB Kab } \\
\text { Lamongan (\%)/Share Agricultural and Fisheris of GDP } \\
\text { by Industr, 2007, 2014 and 2018 in Lamongan (\%) }\end{array}$ \\
\cline { 3 - 5 } & & $\mathbf{2 0 0 7}$ & $\mathbf{2 0 1 4}$ & $\mathbf{2 0 1 8}$ \\
\hline Lamongan & Pertanian/Agriculture & 47.60 & 40.15 & 35.27 \\
& Tanaman pangan/ Crops & 30.00 & 24.02 & 12.33 \\
& Perikanan/Fisheries & 14.98 & 13.84 & 16.98 \\
\hline
\end{tabular}

Sumber: Statistik Kabupaten Lamongan tahun 2008, 2015 dan 2019 (diolah)/

Source: Lamongan Regency in Figure, 2008, 2015 and 2019

Tabel 5 menunjukkan perkembangan share PDRB berdasarkan lapangan usaha. Share perikanan terhadap PDRB, sektor perikanan mempunyai share yang besar di Lamongan. Secara struktur perubahan yang terjadi di Kabupaten Lamongan, terjadi penurunan peran sektor primer (pertanian) yang diikuti oleh peningkatan peranan sektor perdagangan, hotel dan restoran dan industri pengolahan. $\mathrm{Di}$ kabupaten Lamongan sektor perikanan memberikan kontribusi yang besar terhadap PDRB Kabupaten Lamongan. Sektor pertanian (termasuk perikanan memberikan share yang besar terhadap PDRB kabupaten Lamongan yaitu sebesar lebih dari 40\% (tahun 2007 dan 2014), namun perannya semakin menurun tinggal $35,27 \%$ tahun 2017. Meskipun peran sektor pertanian turun, namun peran subsektor perikanan sharenya naik dari 14,98 \% tahun 2007 menjadi 16,98 tahun 2018.

\section{PERANAN NELAYAN SKALA KECIL}

Dampak ekonomi dari aktifitas perikanan dapat dikelompokkan menjadi tiga katagori, yaitu manfaat langsung (direct), tidak langsung (indirect) dan ikutan (induced) (Linberg, 1996). Manfaat

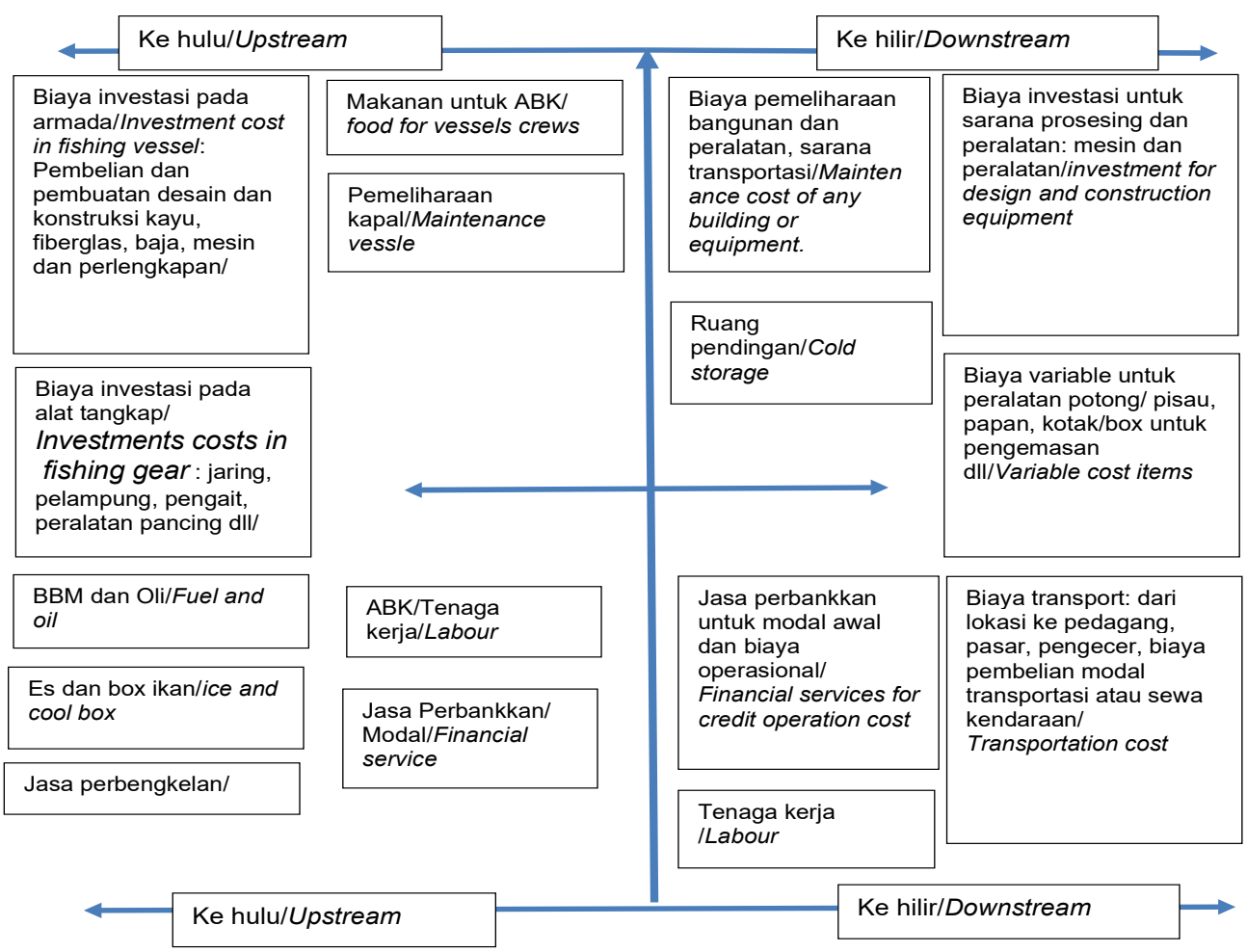

Gambar 2. Upstream dan Downstream Aktifitas Pada Perikanan Tangkap Skala Kecil.

Figure 2. Upstream and Downstream Activities in Small-Scale Capture Fisheries.

Sumber: Bene, 2006 (dimodifikasi)/Sources. Bene. 2006 (modified) 
langsung ditimbulkan dari kegiatan perikanan (penangkapan) yang memerlukan input berupa Tenaga kerja/ABK, bahan bakar minyak (BBM), Es, Air Bersih, perbekalan/ransum dan lain-lain. Input tersebut diperoleh dari sektor lain, hal ini menimbulkan manfaat tidak langsung (indirect benefit). Jika ABK berasal dari daerah setempat/ lokal, maka pengeluaran dari ABK lokal tersebut akan menimbulkan induced benefit dilokasi tersebut. Tidak semua manfaat atau dampak ekonomi tersebut dinikmati oleh masyarakat setempat. Apabila input tersebut didatangkan dari luar daerah atau impor maka perputaran uang tidak menimbulkan indirect benefit tetapi suatu kebocoran (leakage) manfaat. Aliran uang dari aktifitas perikanan ke masyarakat lokal pada akhirnya menciptakan dampak ekonomi dan kebocoran ekonomi. Manfaat atau dampak aktifitas perikanan skala kecil di Kawasan Weru Komplek, dapat diilustrasikan pada gambar berikut (diadaptasi dari Bene, 2006). Aktifitas penangkapan ikan yang dilakukan oleh nelayan akan memberikan dampak langsung.

Keterkaitan tersebut akan membuat perputaran ekonomi di Kawasan Weru Komplek. Aktifitas perikanan ke hulu mampu menggerakkan aktifitas-aktifitas investasi kapal dan alat penangkapan ikan. Kapal-kapal yang dibangun di daerah Lamongan menjadi sumber pendapatan bagi pelaku usahanya. Usaha perikanan juga mampu menggerakkan usaha penyedia pasokan bahan makanan bagi $A B K$, penyedia jasa perbengkelan, penyedia permodalan, penyedia es, air bersih, penyedia bahan bakar dan oli, penyedia jasa keuangan dan lain-lain. Kegiatan perikanan juga mampu menggerakkan perekonomian disektor hilir melalui aktifitas-aktifitas investasi tempat dan mesin pengolahan produk, jasa transportasi, jasa keuangan, cold storage, tenaga kerja, industripengolahan dan lain-lain. Tidak semua manfaat tersebut dapat dinikmati oleh masyarakat setempat, karena sumberdayanya berasal dari luar daerah, hal tersebut menandakan terjadinya kebocoran hasil pembangunan (Rustiadi, Saefulhakim \& Panuju, 2009; Kuncoro, 2012).

\section{PERGESERAN PERAN PEREMPUAN DALAM MANAJEMEN USAHA (PERAN TENGKULAK vS ISTRI NELAYAN)}

Selama ini hubungan keterikatan nelayan dengan tengkulak/langgan telah terjadi dimana kedua belah pihak saling membutuhkan. Hubungan nelayan dengan langgan/tengkulak dilokasi penelitian menggambarkan hubungan kepentingan ekonomi kedua belah pihak. Kasus di Lamongan nelayan berhubungan dengan langgan/tengkulak untuk mendapatkan biaya operasional dengan imbalan berupa hasil tangkapan yang dijual ke tengkulak/langgan. Kedua belah pihak bersepakat secara informal/tidak tertulis tentang hak dan kewajiban. Fungsi-fungsi sosial dari kedua belah pihak masih ada, seperti memberi bantuan pada saat paceklik, bantuan bencana dan bantuan hari raya.

Peranan lembaga non formal Blandongan yang mewadahi nelayan di Weru Komplek berfungsi agar hubungan nelayan dan tengkulak/langgan bisa bersifat saling menguntungkan dan berusaha mengurangi efek negatif dari hubungan tersebut. Hubungan patron client tersebut memberikan keuntungan kepada kedua belah pihak (FerrolSchulte et al., 2014). Keuntungan utama yang diperoleh client antara lain: (1) Kemudahan dalam memperoleh kredit subsisten dan modal investasi (pemberian modal kerja tanpa agunan dan pinjaman pembelian $\mathrm{kapal} / \mathrm{mesin} / \mathrm{alat}$ penangkapan ikan); Keamanan selama musim paceklik (bantuan kemanusiaan pada waktu paceklik); (3) Akses pasar (jaminan hasil tangkapan); (4) Akses informasi (mendapatkan informasi lebih awal dari tengkulak). Sedangkan bagi Patron/nelayan keuntungan utama yang diperoleh: (1) Loyalitas dari nelayan (nelayan akan menjual hasil tangkapan kepada tengkulak); (2) Akses pasar (jaminan hasil tangkapan); (3) Akses informasi (mendapatkan informasi lebih awal dari tengkulak); (4) Akses pasar (jaminan hasil tangkapan); (5) Dukungan politik (misalnya mau menjadi anggota Dewan); (7) Harga produk yang murah (karena tengkulak telah memberikan modal).

Ditengah kuatnya peran tangkulak/langgan dalam pengelolaan sistem usaha perikanan, muncul peran istri nelayan/wanita nelayan dalam manajemen usaha. Sesuai dengan perkembangan informasi dan pengetahuan yang semakin maju, usaha manajemen hasil tangkapan mulai terjadi pergeseran Istri nelayan memainkan peran yang sebelumnya banyak didominasi oleh langgan/ tengkulak.. Semula peran langgan/tengkulak sangat dominan, namun saat ini mulai bergeser peranan tersebut diambil alih oleh istri nelayan. Peranan yang dilakukan oleh istri nelayan ini biasa disebut "mapak" dalam Bahasa Indonesia berarti "menjemput" dimana istri nelayan akan menjemput ke tempatnelayan menambatkan kapal/perahu (TPI) 
untuk melakukan proses grading dan pemasaran ikan hasil tangkapan ke pasar. Peranan istri nelayan ini saat ini telah mampu mengurangi dominasi langgan/tengkulak. Kelebihan, keuntungan dan kekurangan manajemen usaha "mapak" seperti tertera pada Tabel 6. Peran utama yang dijalankan upaya untuk lebih memaksimalkan pendapatan dari usaha penangkapan yang dilakukan oleh nelayan. Kelebihan utama dari peran "mapak" adalah istri nelayan dapat melakukan grading/ pemilahan hasil tangkapan sesuai dengan jenis ikan dan kualitas ikan yang ditangkap. Dengan demikian pada saat menjual istri nelayan dapat menjual dengan harga yang lebih tinggi sesuai dengan jenis ikan dan kualitasnya. Selain memperoleh harga yang lebih baik, pembayaran dilakukan saecara cash sesuai dengan besarnya transaksi. Hal ini tidak terjadi apabila hasil tangkapan dijual ke tengkulak/langgan.

Menurut Harper, Adshade, Lam, Pauly \& Sumaila. (2020) dalam banyak konteks, perempuan juga menjual sebagian hasil tangkapan dan menghasilkan pendapatan. Temuan-temuan tersebut menggarisbawahi peran penting perempuan sebagai produsen langsung dalam rantai nilai perikanan skala kecil, memberikan kontribusi nyata bagi perempuan untuk ketahanan pangan dan mata pencaharian (Harper et al. 2020). Di Oman, peran wanita nelayan/istri nelayan umumnya terlibat dalam pengumpulan, pemungutan dan penangkapan, serta secara eksklusif dalam menangkap, memproses dan memasarkan gastropoda laut (Al Rashid \& Mclean, 2014). Namun demikian, kurangnya data dan penilaian ekonomi perikanan subsisten yang memadai menyebabkan kegiatan perikanan perempuan tidak dimasukkan dalam sebagian besar statistik resmi (Vunisea, 2004). Perikanan skala kecil mempunyai peranan yang penting dalam perekonomian wilayah, dimana keberlanjutan usaha yang bersumber dari perikanan tangkap ditentukan pasokan bahan baku ikan untuk pasar dan industri pengolahan. Nelayan sebagai ujung tombak mata rantai industri perikanan harus mendapat perhatian agar pasokan

Tabel 6. Kelebihan/Keuntungan dan Kekurangan Manajemen Usaha Hasil Tangkapan "Mapak" yang dilakukan oleh Istri Nelayan dibandingkan dengan melalui Tengkulak/Langgan.

Table 6. Advantagess and Weaknesses of "Mapak" Fisheries Product Management by Fishers" Wives compared to middlemen/Traders.

\begin{tabular}{|c|c|c|c|}
\hline No & $\begin{array}{l}\text { Peranan/ } \\
\text { Role }\end{array}$ & $\begin{array}{l}\text { Tengkulak/Langgan } \\
\text { Middlemen }\end{array}$ & $\begin{array}{l}\text { Istri Nelayan/ } \\
\text { Fishers Wifes }\end{array}$ \\
\hline 1. & $\begin{array}{l}\text { Grading jenis dan } \\
\text { kualitas/ Grading } \\
\text { and quality }\end{array}$ & $\begin{array}{l}\text { Borongan (semua hasil dibeli } \\
\text { Tengkulak) dengan kualitas dianggap } \\
\text { rata-rata/Wholesale (all purchased by } \\
\text { middlemen) of average quality }\end{array}$ & $\begin{array}{l}\text { Melakukan grading dan pemilahan } \\
\text { jenis ikan berdasar ukuran dan } \\
\text { kualitas/Grading and sorting based } \\
\text { on size and quality }\end{array}$ \\
\hline 2 & Harga/Price & $\begin{array}{l}\text { Harga rata-rata, tanpa } \\
\text { memperhitungkan jenis dan kualitas. } \\
\text { Average price, regardless of type and } \\
\text { quality. }\end{array}$ & $\begin{array}{l}\text { Harga lebih tinggi, ditentukan jenis } \\
\text { dan kualitas ikan/Higher prices, } \\
\text { determined the type and quality of } \\
\text { fish. }\end{array}$ \\
\hline 3 & $\begin{array}{l}\text { Pembayaran/ } \\
\text { Payment }\end{array}$ & $\begin{array}{l}\text { Ada tenggat waktu dan tidak dibayarkan } \\
\text { penuh/deadline }\end{array}$ & $\begin{array}{l}\text { Pembayaran tunai dari pembeli/ } \\
\text { Cach }\end{array}$ \\
\hline 4 & $\begin{array}{l}\text { Hubungan/ } \\
\text { Relationship }\end{array}$ & $\begin{array}{l}\text { Ikatan antara kedua belah pihak/Patron } \\
\text { client }\end{array}$ & $\begin{array}{l}\text { Hubungan bisnis antar pembeli } \\
\text { dan penjual, tidak ada ikatan } \\
\text { kedua belah pihak/ Relationship } \\
\text { between seller and buyer }\end{array}$ \\
\hline 5. & $\begin{array}{l}\text { Ikatan Sosial/ } \\
\text { Social }\end{array}$ & $\begin{array}{l}\text { Biasanya disertai ikatan sosial, dimana } \\
\text { langgan/ tengkulak memberikan } \\
\text { jaminan sosial pada saat musim } \\
\text { paceklik/ with accompanied by social } \\
\text { ties }\end{array}$ & $\begin{array}{l}\text { Tidak ada ikatan sosial kedua } \\
\text { belah pihak/ not accompanied by } \\
\text { social ties }\end{array}$ \\
\hline 6. & $\begin{array}{l}\text { Kepastian dan } \\
\text { resiko/ Certainty } \\
\text { and risk }\end{array}$ & $\begin{array}{l}\text { Semua hasil tangkapan dibeli oleh } \\
\text { tengkulak/ all catches bought by } \\
\text { middlemen }\end{array}$ & $\begin{array}{l}\text { Ada resiko, tidak semua hasil } \\
\text { tangkapan terjual /There is a risk, } \\
\text { not all catches are sold }\end{array}$ \\
\hline
\end{tabular}

Sumber: Hasil wawancara/diskusi dengan berbagai sumber dilokasi penelitian, 2015 and 2019/

Source: Interviews discussions with various sources at the research location, 2015 and 2019 
ikan tetap stabil. Dari sudut pandang sumber daya ikan, tingginya indek ketidakstabilan menjadi salah satu indikator bahwa telah terjadi upaya ekstraksi sumber daya yang berlebihan. Oleh karena itu kestabilan dari sisi sumber daya perlu dijaga agar kegiatan usaha yang bersumber dari perikanan dapat tetap berjalan sehingga sumber pertumbuhan ekonomi wilayah tetap terjaga, pada akhirnya akan menjaga kestabilan ekonomi wilayah. Secara ekonomi stabilitas pasokan akan menjaga mata rantai usaha dapat berkesinambungan dan mampu menggerakkan perekonomian wilayah. Saling ketergantungan antara nelayan dengan masyarakat sekitar sangat tinggi, perikanan dengan sumber daya pelagis kecil dan demersal pada umumnya mempunyai keterkaitan yang lebih tinggi. Keterkaitan ke hilir menghasilkan nilai tambah dari kegiatan-kegiatan usaha pengolahan ikan menjadi produk-produk jadi. Peranan pedagang perantara lebih kuat di daerah pesisir yang mempunyai sumber daya perikanan pelagis kecil dan demersal. Rantai nilai pada perikanan skala kecil menunjukan bahwa nilai tamb ah banyak dinikmati oleh para pelaku usaha lokal.

Dalam menjalankan peran "mapak" istri nelayan berbagi peran dengan suami yang bertindak sebagai nelayan. Seperti ketahui nelayan di Weru Komplek pada umumnya adala nelayan harian/one day fishing, dimana nelayan biasanya bernagkat pada malam hari atau dini hari dan pulang ke TPI sekitar pukutl 09.00-11.00. Pembagian peran antara suami sebagai nelayan dan istri sebagai bagian manajemen pengelolaan hasil tangkapan seperti pada Gambar 3 dan Gambar 4.

Gambar 3 mengilustrasikan aktifitas suami sebagai nelayan, yang biasa berangkat melaut pada malah hari atau dini hari menggunakan perahu/kapal yang berukuran kurang dari 5 GT dengan jumlah ABK 2-5 orang. Nelayan akan pulang ke TPI sekitar pukul 09.00 - 11.00, pada saat nelayan merapat ke TPI disinilah per29an istri nelayan menjalankan fungsi-fungsi "mapak" mulai melakukan pemilahan/grading hasil tangkapan, kemudian membawa hasil tangkapn ke pasar dengan menggunakan motor/ojek becak motor. Selanjutnya istri nelayan melakukan penjualan ikan di pasar sampai sore hari sekitar jam 15.00 WIB. Pada saat istri menjalankan peran "mapak" suami sebagai nelayan dapat pulang ke rumah untuk istirahat. Kerjasama peran "mapak" ini waktu yang digunakan akan lebih efisien dan menjadaikan istri nelayan lebih produktif.

Interaksi istri nelayan selama menangani hasil tangkapan menambah interaksi istri nelayan dengan para pelaku usaha yang ada di TPI maupun di pasar. Interaksi tersebut dapat menjadi kegiatan yang lebih produktif dimana istri nelayan bisa memainkan peran sebagai penghubung dengan Bank dalam penyaluran KUR. Di Kawasan Weru Komplek sebagian masyarakatnya melakukan usaha pengolahan produk ikan memanfaatkan hasil tangkapan atau dengan cara membeli ikan di pasar. Produk olahan antara lain petis, terasi, kerupuk ikan/kerupuk cumi, ikan asin, dan abon ikan. Kekurangan modal bisa dipenuhi dari pinjaman dari BRI melalui skema KUR. Sertifikat ijin usaha (PIR-T) bisa dijaminkan sebagai agunan dengan besar pinjaman Rp3000.000,Rp5.000.000.

Fokus kebijakan untuk mengembangkan perikanan skala kecil di Lamongan dengan karakteristik pasar yang masih lebih "tradisional" dimana perlu pengembangan untuk meningkatkan skala usaha. dan perlu adanya diversifikasi produk dan pengembangan pasar lokal.

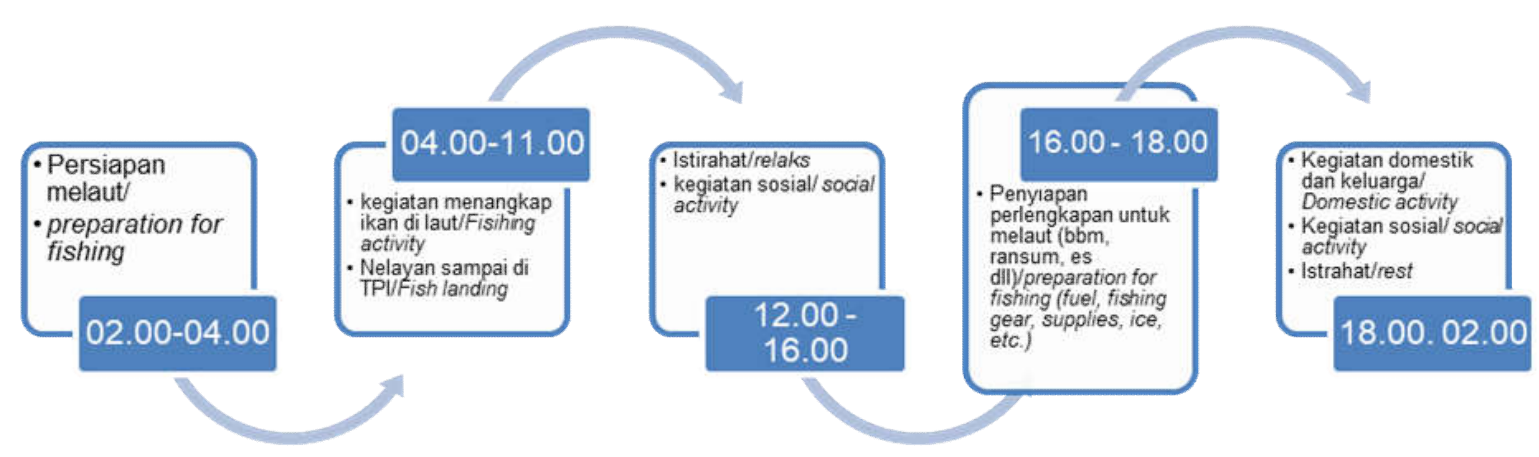

Gambar 3. Aktifitas Nelayan Selama 24 Jam di Lokasi penelitian.

Figure 3. Fishers Activities for 24 Hours at the Research site. 


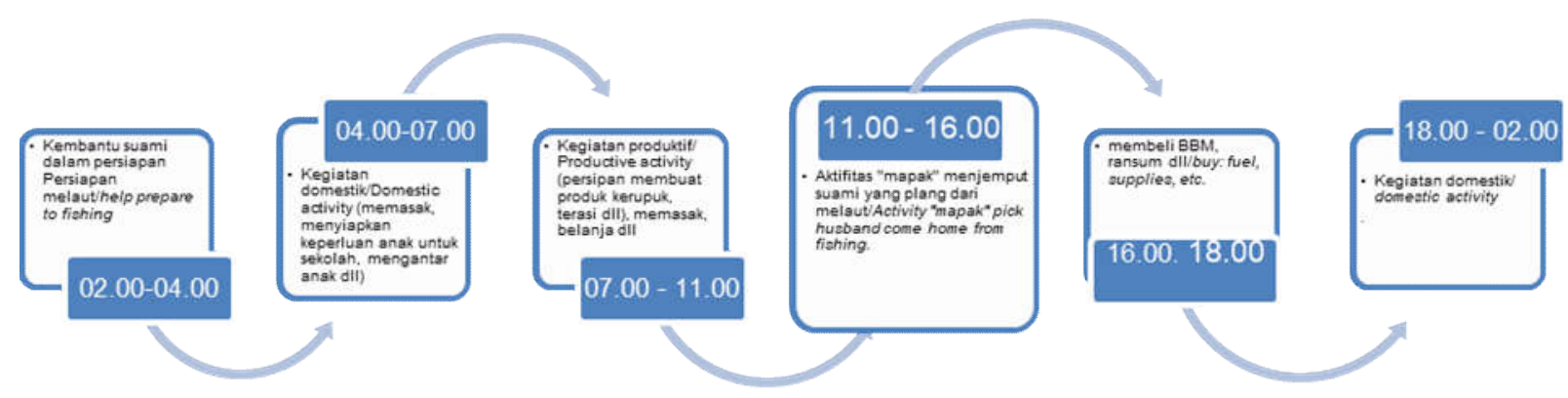

Gambar 4. Aktifitas Istri/lbu Rumah Tangga Sebagai Bagian dari Manajemen Usaha Selama 24 jam.

Figure 4. The role of the Wife/Housewife as Part of Fisheries Business Management for 24 Hours at the Research Location.

Hubungan yang saling menguntungkan kedua belah pihak merupakan faktor penting yang harus dikemukakan, karena hubungan kedua belah pihak adalah hubungan ketergantungan yang bersifat mutualisme. Oleh karena itu kedua belah pihak harus memperoleh manfaat positif dari interaksi tersebut. Hubungan timbal balik yang saling menguntungkan kedua belah pihak harus lebih dikedepankan. Saling ketergantungan yang merupakan salah satu faktor pengikat hubungan patron-client tersebut. Nilai positif keuntungan yang diperoleh kedua belah pihak tidak hanya sematamata mengenai bentuk uang (ekonomi) namun motif-motif sosial dan politik juga mempunyai nilai positif dalam hubungan patron client.

Hubungan keterkaitan di Lamongan dengan karakter perikanan yang pasarnya masih bersifat "tradisional" lebih kuat dari pada daerah/ lokasi dimana karakteristik pasarnya lebih maju dan terbuka (Wardono \& Fauzi, 2016). Fokus kebijakannya adalah meningkatkan skala usaha, diversifikasi produk dan pengembangan pasar lokal.

Wilayah pesisir dengan sumber daya perikanan pelagis kecil dan demersal, mempunyai kecenderungan yang lebih sensistif dan responsif terhadap sumber permodalan. Kecenderungan tersebut didukung oleh faktor nelayan yang mempunyai status kapal milik sendiri, lama kepemilikan dan jumlah ABK yang lebih banyak. Implikasinya adalah membuka peluang akses permodalan yang murah dan mudah, salah satunya adalah modal Kredit Usaha Rakyat (KUR) BRI dan Lembaga Pengelola Modal Usaha Kelautan dan Perikanan (LPMUKP). Semakin mudah dan murah sumber-sumber permodalahn tersebut, dapat mengurangi ketergantungan dengan sumber permodalahn yang berasal dari tengkulak/ langgan. Peran penggalangan modal tersebut dapat dilakukan oleh istri nelayan/wanita nelayan yang mampu memfasilitasi/nara hubung antara peminjam dengan Lembaga permodalan (Bank dan Sumber lainnya) melalui program KUR.

Dukungan kelembagaan formal yang bisa menjalankan peran seperti fungsi perantara/langgan dengan mengadopsi sistem yang diterapkan oleh langgan yaitu kemudahan dan fleksibilitas dalam waktu, jumlah dan tenggat waktu pengembalian pinjaman. Kebijakan pengembangan perikanan tangkap skala kecil perlu mempertimbangkan kondisi sosial budaya dan sumber daya yang ada diwilayah tersebut. Pengembangan sumber pemodalan lebih diperlukan pada daerah pesisir dengan sumber daya perikanan pelagis kecil dan dermersal. Fleksibilitas dan kemudahan persyararatan menjadi kekuatan utama mengapa langgan bisa bersinergi dengan nelayan. Kedua belah pihak merasa memperoleh "keuntungan" dari sistem yang berlaku.

Aktifitas perikanan mampu menciptakan nilai tambah yang dinikmati oleh para pelaku usaha. Kecenderungannya nilai tambah dinikmati oleh sektor pemasaran (pedagang pengumpul, pedagang perantara, pedagang pengecer, dan sektor industri), sedangkan nelayan kadang mendapat proporsi nilai tambah yang relatif kecil. Kondisi ini sebagai salah satu akibat tidak seimbangnya posisi tawar nelayan terhadap para pedagang, dimana sumber modal berasal dari para pedagang perantara/langgan.

Implikasi kebijakan kelembagaan lokal diharapkan mampu meningkatkan posisi tawar nelayan. Blandongan bisa menjadi salah alternatif kelembagaan lokal yang menjalakan peran sebagai fasilitator agar posisi nelayan lebih kuat. Semakin majunya informasi mampu meningkatkan posisi 
tawar nelayan, perkembangan harga dengan cepat dapat diakses oleh nelayan. Keberadaan pedagang perantara masih dibutuhkan oleh nelayan selama belum ada kelembagaan formal yang mampu memerankan fungsi pedagang perantara/ langgan (flesibilitas dan kemudahan), namun pedagang perantara tidak dapat menetapkan harga sesuai kemauannya sendiri.

Fakta yang muncul tidak ada pihak yang ingin menyelesaikan hutang-piutang yang berjalan, selama kepercayaan di antara tengkulak/langgan dengan nelayan tersebut masih ada, tidak ada alasan untuk khawatir tentang transaksi keuangan (penyelesaian hubungan hutang piutang). Menurut Manez \& Ferse (2010) berdasarkan indikator pasar, pelanggan/tengkulak berfungsi terutama sebagai inovator bisnis dengan kesediaan untuk membeli semua komoditas ikan dan memenuhi kebutuhan yang diperlukan "client". Berdasarkan analisis tersebut pola interaksi nelayan-pedagang perantara/ langgan dimana lokasi berpengaruh sangat kuat, maka kebijakan untuk mengembangkan perikanan skala kecil lebih pada lokasi dimana karakteristik sumber daya perikanan lebih didominasi sumber daya pelagis kecil dan demersal, dengan karakteristik pasar yang masih lebih "tradisional" dari pada daerah yang mempunyai karakteristik sumber daya pelagis besar dan karakteristik pasar yang lebih terbuka. Dukungan kelembagaan formal yang bisa menjalankan peran seperti fungsi yang selama ini diperankan oleh pedagang perantara/ langgan dengan mengadopsi sistem yang diterapkan oleh langgan yaitu kemudahan dan fleksibilitas dalam waktu, jumlah dan tenggat waktu pengembalian pinjaman.

Manurut Anna (2014) wanita nelayan memainkan peran utama dalam ekonomi rumah tangga di pantai utara Jawa, Indonesia. Namun demikian salah satu masalah utama bagi wanita nelayan untuk mengembangkan keterampilan mereka dalam bisnis adalah kurangnya modal keuangan (Anna, 2014). Hal yang berbeda terjadi di tiga wilayah perikanan di India, dimana perubahan sebagian besar sistem produksi pangan dan perubahan teknologi, seperti mekanisasi, sering mengakibatkan semakin termaginalkan peran perempuan dari peran tradisional yang telah biasa Dilakukan (Gopal, Edwin \& Meenakumari, 2014). Terjadinya perubahan-perubahan ini, membutuhkan intervensi khusus untuk memberi kesempatan bagi wanita nelayan terhadap akses yang lebih besar ke manfaat perikanan (Gopal et al., 2014)
Produksi perikanan hasil tangkapan nelayan harus segera dipasarkan, langsung dikonsumsi atau diolah terlebih dahulu, karena produk perikanan mempunyai sifat mudah rusak. Hasil tangkapan nelayan yang ada di kawasan Weru komplek biasanya ada yang dijual ke tengkulak dan ada yang dijual langsung ke pasar. Pasar sebagai tempat aktifitas transaksi jual beli ikan juga berada di kawasan Weru komplek berdekatan dengan TPI. Pasar ini beroperasi pada siang hari jam 11.00-16.00, aktifitas pasar dimulai setelah nelayan menurunkan hasil tangkapan dan dibawa ke pasar. Penjualan ikan ke pasar dijalankan oleh istri nelayan ke beberapa penjual sehingga diperoleh pendapatan yang lebih baik, dari pada hasilnya langsung dijual ke tengkulak/langgan

Langgan/pedagang perantara memainkan peranan yang penting dalam pembentukan nilai tambah. Nelayan memerlukan jaminan produksi hasil tangkapannya dapat terjual semuanya, dan langgan/pedagang perantara perlu mendapat jaminan produk yang dapat dipasarkan dari nelayan (esensi hubungan patron-client). Hal tersebut memunculkan hubungan yang saling menguntungkan (Ferrol-Shulte et al., 2014).

\section{IMPLIKASI KEBIJAKAN}

Perikanan skala kecil mempunyai peran yang penting dalam perekonomian suatu wilayah. Kemampuannya menggerakkan perekonomian menjadi penopang utama bagi para pelakunya (nelayan, pedagang, pengepul, pengecer, penyedia sarana dan prasarana, penyedia jasa angkutan, pengolahan dan lain-lain). Peranan tengkulang/ langgan memang masih kuat namun peranan istri nelayan sebagai bagian dari manajemen pengelolaan hasil tangkapan menjadi semakin penting. "Mapak" merupakan salah satu upaya perbaikan manajemen usaha penangkapan yang dilakukan oleh istri nelayan. Kelebihan utama "mapak" adalah mampu mengurangi ketergantungan dengan tengkulak, bisa mendapatkan harga yang lebih baik, pengelolaandan pemanfaatan keuangan hasil tangkapan menjadi terkontrol. Penggalangan dana operasional biasa dilakukan melalui kegiatan pengajian ibu-ibu dan tabungan anak-anak sekolah. Model manajemen usaha perikanan skala kecil di Weru Komplek bisa menjadi model pengelolaan usaha perikanan. Peningkatan wawasan dan pengetahuan dan keterampilan bagi ibu-ibu istri nelayan sangat diperlukan agar bisa berperan dalam pengelolaan usaha hasil 
penangkapan.

Kebijakan untuk mengembangkan perikanan skala kecil harus memperhatikan potensi sumber daya perikanan sebagai penggerak utama perekonomian disuatu kawasan. Perlu keterpaduan sumber daya dengan pelaku uasaha (nelayan, pedagang, penyedia sarana dan prasaran pengolah dan penyedi jasa) sehingga mampu menggerakkan perekonomian berbasis sumber daya perikanan. Peningkatan peran istri nelayan/ wanita nelayan dapat mengurangi ketergantungan terhadap tengkulak sekaligus dapat memperbaiki manajemen usaha dalam rumah tangga. Diperlukan penguatan kepasitas dan kemampuan agar perannya bisa lebih besar dalam pengelolaan usaha perikanan. Dalam jangka panjang diharapkan akan terjadi perbaikan kesejahteraan masyarakat melalui perbaikan manajemen usaha perikanan. Peningkatan peran istri nelayan/wanita nelayan diharapkan mampu menyeimbangkan pola hubungan dengan tengkulak/langgan, agar menghindarkan perilaku hubungan yang bersifat eksploitatif terhadap nelayan. Pemerintatah harus mereposisi peran tengkulak/langgan kedalam sistem perkreditan masyarakat: dimana tengkulak/ langgan sebagai instrumen penting dan dapat menjalankan fungsi sosial dalam masuyarakat perikanan skala kecil. Keberpihakan pemerintah (Pusat dan Daerah) untuk meningkatkan peran perikanan skala kecil melalui skala prioritas program/bantuan, seperti dalam alokasi anggaran (Program bantuan Kapal dan KUR) untuk mempermudah dan memberikan kepastian dalam akses input. KUR sebagai skema sumber pembiayaan murah, menjadi salah satu instrumen penting dalam upaya meningkatkan skala ekonomi pelaku usaha, dimana istri nelayan/ wanita nelayan bisa menjadi fasilitator atau nara hubung.

\section{UCAPAN TERIMA KASIH}

Penulis mengucapkan terimakasih kepada berbagai pihak atas keterlibatan dan bantuan baik secara material maupun non material sehingga karya tulis ini dapat diselesaikan dengan baik. Untuk itu penulis mengucapkan terimas kasih yang sebesar-besarnya kepada (1). Kepala Balai Besar Riset Sosial Ekonomi Kelautan dan Perikanan; (2). Kepala Dinas Kelautan dan Perikanan Kabupaten Lamongan dan staf dilokasi penelitian atas kerjasamanya sehingga penelitian dapat berjalan dengan lancar. (3). Masyarakat pelaku usaha perikanan di lokasi penelitian yang telah banyak membantu terlaksananya penelitian, (4). Berbagai pihak lain yang tidak disebutkan satu persatu yang telah berkontribusi pada Karya tulis ini.

\section{PERNYATAAN KONTRIBUSI PENULIS}

Kontributor dalam karya tulis ilmiah adalah Budi Wardono sebagai kontributor utama dan Toha Muslih sebagai kontributor anggota yang sudah disepakati bersama-sama untuk diketahui semua pihak yang berkepentingan.

\section{DAFTAR PUSTAKA}

Al Rashid, K. M. \& Mclean, E. (2014). Contribution of Small-Scale Fisheries to the Livelihoods of Omani Women: A Case Study of the Al Wusta Governorate. Asian Fisheries Science: Special Issue 27S: 135-149.

Anna, Z. (2014). The Case of Women Fish Vendors in North Coast of Java. Asian Fisheries Science Special Issue 27S: 211-224.

Bene, C. (2006). Small-Scale Fisheries: Assessing Their Contribution To Rural Livelihoods In Developing Countries. FAO Fisheries Circular. No. 1008. Rome, FAO. 2006. 46p.

BPS [Badan Pusat Statistik Kabupaten Lamongan]. (2015). Lamongan Dalam Angka 2014. Badan Pusat Statistik Kabupaten Lamongan.

BPS [Badan Pusat Statistik Kabupaten Lamongan]. (2016). Lamongan Dalam Angka 2015. Badan Pusat Statistik Kabupaten Lamongan.

BPS [Badan Pusat Statistik Kabupaten Lamongan]. (2018). Lamongan Dalam Angka 2017. Badan Pusat Statistik Kabupaten Lamongan.

BPS [Badan Pusat Statistik Kabupaten Lamongan]. (2019). Lamongan Dalam Angka 2018. Badan Pusat Statistik Kabupaten Lamongan.

Fauzi, A. \& Anna, Z. (2010). The Java Sea Small-Scale Fisheries in Changing Environment Experiences From Indonesia IIFET 2010. Montpellier Proceedings.

Fauzi, A. (2010). Ekonomi Perikanan: Teori, Kebijakan, dan Pengelolaan. Penerbit PT. Gramedia Pustaka Utama. Jakarta.

Ferrol-Schulte, D., Ferse, S.C.A. \& Glaser, M. (2014). Patron-Client Realationships, Livelihoods and Natural Resources Management in Tropical Coastal Communities. Ocean and Coastal Management ,100: 63-73.

Gopal, N., Edwin, L. \& Meenakumari, B. (2014). Transformation in Gender Roles with Changes in Traditional Fisheries in Kerala, India. Asian Fisheries Science, Special Issue 27S: 67-78. 
Harper, S., Adshade, M., Lam, V.W.Y., Pauly, D. \& Sumaila, U.R. (2020). Valuing invisible catches: Estimating the global contribution by women to small-scale marine capture fisheries production. PLOS ONE 15(3). DOI: https://doi.org/ 10.1371/ journal.pone.0228912.

KKP [Kementerian Kelautan dan Perikanan]. (2015). Kinerja Sektor Perikanan Indonesia 2015. Kementerian Kelautan dan Perikanan. Jakarta.

KKP [Kementerian Kelautan dan Perikanan]. (2019). Kelautan dan Perikanan Dalam Angka Tahun 2018. Kementerian Kelautan dan Perikanan. Jakarta.

Kramer, R. A, Simanjuntak S.M. \& Liese C. (2002). Migration and fishing in Indonesian coastal villages. AMBIO: A Journal of the Human Environment 31:367-72.

Kuncoro, M. (2012). Perencanaan Daerah: Bagaimana Membangun Ekonomi Lokal, Kota dan Kawasan. Penerbit Salemba Empat. Jakarta.

Linberg, K. (1996). The Economic Impact of Ecotourism. Retrieved: www://.ecotourism.ee/ oko/kreg.html.

Manez, K. S. \& Ferse, S.C.A. (2010). The History of Makassan Trepang Fishing and Trade, PLoS ONE, 5(6): 1-8.

Ridho, A. R. \& Susilowati, D. (2018). Analisis Sektor Pertanian, Kehutanan, Perikanan Terhadap PDRB Di Kabupaten Lamongan. Jurnal IImu Ekonomi, 2(1) pp14 - 25.

Rustiadi, E., Saefulhakim, S. \& Panuju, D. R. (2009). Perencanaan dan Pengembangan Wilayah. Cresspent Press dan Yayasan Obor Indonesia. Jakarta

Sangun, L., Güney, O. I. \& Berk, A. (2018). Economic efficiency performance of small-scale fisheries in the East Mediterranean coast of Turkey. New Medit. XVII(4) DOI: 10.30682/nm1804f.

Sievanen, L. (2014). How do small-scale fishers adapt to environmental variability? Lessons from Baja California, Sur, Mexico. Maritime Studies, 13:1-19.

Sudarmo, A. P, Baskoro, M.S., Wiryawan, B., Wiyono, E, S. \& Monintja, D. R. (2015). Analysis of Production Factors of Small-Scale Fisheries using Arad Nets in Tegal City, Indonesia. Developing Country Studies 5:98-104.

Vunisea, A. (2004). The challenges of seafood marketing in Fiji. SPC Women in Fisheries Information Buletin.;3-8. Diakses pada tanggal 28 Mei 2020, retrieved from Retraiev Retrieved: https:// coastfish.spc.int/en/publications/bulletins/ women-in-fisheries.
Wardono, B. \& Fauzi, A. (2016). Peran "Bantal Sosial" pada Mata Pencaharian Nelayan Skala Kecil di Jawa. Jurmal Sosial Ekonomi Kelautan dan Perikanan, 11(2):225-235. DOI: http://dx.doi. org/10.15578/jsekp.v11i2.3831.

Wardono, B., Fauzi, A., Fahrudin, A. \& Purnomo, A.H. (2015). Total Faktor Produktifitas dan Indeks Instabilitas Perikanan Tangkap. Junral Sosial Ekonomi Kelautan dan Perikanan, 10(1):35-46. DOI: http://dx.doi.org/10.15578/jsekp.v10i1.1246.

Zeller, D., Booth, S., Davis, G. \& Pauly, D. (2007). Re-Estimation Of Small-Scale For U.S. Flag-Associated Islands In The Western Pacific: the last 50 years. U.S. Fisheries Bulletin 105: 266-277. 